\title{
Mina53, a novel molecular marker for the diagnosis and prognosis of gastric adenocarcinoma
}

\author{
JING XING $^{1,3^{*}}$, KE WANG $^{2 *}$, PENG-WEI LIU ${ }^{1}$, QI MIAO $^{1}$ and XIAO-YU CHEN ${ }^{1}$ \\ ${ }^{1}$ Department of Gastroenterology and Hepatology, Renji Hospital, School of Medicine, Shanghai Jiaotong University, \\ Division of Gastrointestinal Pathology, Shanghai Institute of Digestive Disease, Shanghai 200001; \\ ${ }^{2}$ Department of Gastroenterology, Henan Staff Hospital, Zhengzhou, Henan 450002, P.R. China
}

Received August 5, 2013; Accepted October 3, 2013

DOI: $10.3892 / o r .2013 .2918$

\begin{abstract}
Mina53 is a direct novel target protein of Myc. The present study investigated the expression of mina53 and c-myc in gastric carcinoma and the relationship between Mina53 expression and clinicopathological features. The expression levels of mina53 and c-myc mRNA and protein in gastric cancers and the adjacent normal tissues from 12 patients were assessed by laser-capture microdissection (LCM) combined with quantitative polymerase chain reaction (qPCR) and western blotting, respectively. Immunohistochemical analysis was used to evaluate the expression of the Mina53 protein in normal gastric tissues $(n=30)$, chronic atrophic gastritis without intestinal metaplasia $(n=44)$, intestinal metaplasia $(n=34)$, gastric dysplasia $(n=36)$, intestinal-type gastric carcinoma (IGC) $(n=30)$ and diffuse-type gastric carcinoma (DGC) $(n=34)$. The correlation between expression of mina53 and patient survival time was also investigated. The expression levels of mina53 and $c$-myc mRNA in the gastric carcinomas were found to be higher when compared to these levels in the adjacent normal tissues. In addition, the expression levels of Mina53 and c-Myc protein in gastric carcinomas were higher when compared with levels in the adjacent normal epithelium. mina53 expression was significantly increased during gastric carcinogenesis and
\end{abstract}

Correspondence to: Professor Xiao-Yu Chen, Department of Gastroenterology and Hepatology, Renji Hospital, School of Medicine, Shanghai Jiaotong University, Division of Gastrointestinal Pathology, Shanghai Institute of Digestive Disease, Shanghai 200001, P.R. China E-mail: xiaoyu64@sh163.net

Present address: ${ }^{3}$ Department of Digestive Disease, Affiliated Hospital of Nanjing University of Traditional Chinese Medicine, Nanjing 210029, P.R. China

${ }^{*}$ Contributed equally

Abbreviations: IGC, intestinal-type gastric carcinoma; DGC, diffuse-type gastric carcinoma; LCM, laser-capture microdissection; RT-real-time PCR, reverse transcription real-time polymerase chain reaction

Key words: c-Myc, Mina53, gastric adenocarcinoma, laser-capture microdissection, Lauren's classification was correlated with different clinicopathological factors in IGC and DGC. The prognosis of patients with low expression of Mina53 was more favorable when compared to the prognosis of patients with high expression of Mina53. mina53 expression was gradually elevated during gastric carcinogenesis, and the overexpression of mina53 was correlated with different clinicopathological features between DGC and IGC cases. Furthermore, the prognosis of gastric carcinoma patients was significantly correlated with the expression of Mina53.

\section{Introduction}

Gastric adenocarcinoma is the second leading cause of cancerrelated mortality worldwide (1), and its prognosis mainly depends on early detection and the appropriate treatment (2). In spite of the use of endoscopy with biopsy for diagnosis and health screening, due to the relatively asymptomatic nature of the disease in early stages, the majority of patients are diagnosed at an advanced stage (3). Although surgical intervention and chemotherapy have significantly improved patient outcome, the curative ratio for gastric carcinoma remains quite low (4). Therefore, the identification of available biomarkers is an urgent goal for the early detection and treatment of gastric cancer.

The myc proto-oncogene family mainly includes c-myc, $\mathrm{N}-m y c$ and L-myc, which are involved in cell growth, cell cycle progression and genome instability through many other genes $(5,6)$. Although deregulation of c-myc is known to be related to tumorigenesis of digestive system neoplasms (5), the specific mechanisms are still not fully understood. Mina53 is a recently identified novel myc target gene, whose expression was found to be directly induced by the oncogene c-myc, encoding a protein localized in the nucleus with a molecular weight of $53 \mathrm{kDa}(7)$. Studies have shown that mina53 expression levels are elevated in human colon cancer (8), esophageal squamous cell carcinoma (9), hepatocellular carcinoma (10) and cholangiocarcinoma (11). However, quantitive investigation of mina53 expression has not been carried out, and there are only a few studies concerning mina53 expression in gastric carcinoma.

Laser-capture microdessection (LCM) is a newly developed technology by which the heterogeneity of tissues is satisfactorily resolved in situ (12) and has been widely used 
in gastric carcinoma research (13-16). In the present study, we examined the expression of mina53 in the gastric adenocarcinoma tissues quantitively by LCM combined with real-time polymerase chain reaction (real-time PCR) or western blot analysis. Lauren's classification is an important classification for scientific research. Therefore, the expression of Mina53 during gastric carcinogenesis and its correlation with clinicopathological factors in intestinal gastric carcinoma (IGC) and diffuse gastric carcinoma (DGC) was also immunohistochemically investigated. The correlation between the expression of mina53 and patient survival time was also investigated.

\section{Materials and methods}

Patients and samples. For real-time quantitative PCR detection, 12 pairs of human gastric tumor tissues and their adjacent normal gastric tissues were obtained within $30 \mathrm{~min}$ after surgical resection at Renji Hospital, Shanghai Jiaotong University in 2011. Twelve of these cases were chosen to extract proteins for western blot analysis. These samples were frozen immediately in liquid nitrogen for $20 \mathrm{sec}$ and then stored at $-80^{\circ} \mathrm{C}$ until use. For immunohistochemical examinations, formalin-fixed paraffin-embedded (FFPE) samples were obtained from 64 patients who underwent surgery for gastric carcinoma. The specimens consisting of 30 normal gastric tissues, 44 chronic atrophic gastritis without intestinal metaplasia, 34 intestinal metaplasia, 36 dysplasia were obtained by biopsy during July 2009 and June 2010 at Renji Hospital. All of the patients provided informed consent, and the study protocol was approved by the Ethics Committee of Renji Hospital. An experienced gastrointestinal pathologist (X.-Y. Chen) evaluated the tumor stage and grade by microscopic examination of the samples following laser-capture microdissection.

Fresh-frozen samples were embedded in optimal cutting temperature compound (Sakura Finetek, Torrance, CA, USA) and then serially cut into $8-\mu \mathrm{m}$ sections in a cryostat at $-20^{\circ} \mathrm{C}$. The first section was mounted on ordinary glass slide and stained with H\&E for diagnosis, and the other was mounted on an ethylene vinyl acetate (EVA) membrane, followed by incubation in $70 \%$ ethanol $(1 \mathrm{~min}), \mathrm{ddH}_{2} \mathrm{O}(10 \mathrm{sec})$, Mayer's hematoxylin (30 sec), twice $\mathrm{ddH}_{2} \mathrm{O}(20 \mathrm{sec})$, eosin $(5 \mathrm{sec})$, $95 \%$ ethanol (30 sec) and $100 \%$ ethanol (1 min). After airdrying, the sections were subjected to laser-capture using an LMD system (Leica Microsystems, Wetzlar, Germany), and the cells of interest were selectively collected following the manufacturer's recommendations within $40 \mathrm{~min}$. In order to harvest a sufficient amount of cells, $8 \mathrm{~h}$ was required for real-time PCR and $15 \mathrm{~h}$ for western blot analysis, respectively. Each dissection was determined to be $>95 \%$ homogeneous by review of the histologic sections. The captured malignant and normal cells were preserved in $0.5-\mathrm{ml}$ microcentrifuge tubes containing $200 \mu \mathrm{l}$ TRIzol reagent for isolating total RNA or containing nothing for extracting protein and then stored at $-80^{\circ} \mathrm{C}$ until use.

$R N A$ extraction and RT-PCR. RNA was isolated from the captured cells using the Optimum FFPE RNA Isolation kit (Ambion, Austin, TX, USA) following the recommended manufacturer's instructions. Chloroform (40 $\mu \mathrm{l})$ was added to each tube, and the tubes were shaken violently by hand for $15 \mathrm{sec}$ before incubation at room temperature for $5 \mathrm{~min}$. After centrifugation at $12,000 \mathrm{rpm}$ for $15 \mathrm{~min}$ at $4^{\circ} \mathrm{C}$, the aqueous layer was transferred to a $1.5-\mathrm{ml}$ Eppendorf tube. Glycogen (1 $\mu \mathrm{l})(10 \mu \mathrm{g} / \mu \mathrm{l})$ carrier and $100 \mu \mathrm{l}$ isopropanol were added successively and precipitation was carried out at room temperature for $10 \mathrm{~min}$ followed by centrifugation at $12,000 \mathrm{rpm}$ for $15 \mathrm{~min}$ at $4^{\circ} \mathrm{C}$. The RNA pellet was washed in $500 \mathrm{ml} 75 \%$ ethanol, dried and redissolved in $20 \mu \mathrm{l}$ diethylpyrocarbonatetreated RNase-free water before storing at $-80^{\circ} \mathrm{C}$. RNA samples were treated with DNase (Roche Diagnostics Corp., Indianapolis, IN, USA), and then reverse transcription was performed using $4 \mu \mathrm{l}$ of $5 \mathrm{X}$ PrimeScipt ${ }^{\mathrm{TM}}, 1 \mu \mathrm{l}$ of Oligo(dT) primer $(50 \mu \mathrm{M}), 1 \mu \mathrm{l}$ of random 6 mers $(100 \mu \mathrm{M}), 1 \mu \mathrm{l}$ of PrimeScript $^{\mathrm{TM}}$ RT Enzyme Mix I, x $\mu \mathrm{l}(1 \mu \mathrm{g})$ of total RNA and (13-x) $\mu \mathrm{l}$ of RNase-free $\mathrm{H}_{2} \mathrm{O}$ in a total volume of $20 \mu \mathrm{l}$, followed by incubation at $37^{\circ} \mathrm{C}$ for $15 \mathrm{~min}$ (first-strand synthesis) and at $85^{\circ} \mathrm{C}$ for $5 \mathrm{sec}$ (inactivation of the reverse transcriptase) then the samples were maintained at $4^{\circ} \mathrm{C}$ until use.

Real-time quantitative PCR. Real-time quantitative PCR was performed using the ABI PRISM 7300 sequence detection system (ABI-7300H; Applied Biosystems, Foster City, CA, USA) in a $10-\mu 1$ reaction system including $5 \mu \mathrm{l}$ of SYBR ${ }^{\circledR}$ Premix Ex Taq ${ }^{\mathrm{TM}}$ II (2X) (Takara Corp.) $0.4 \mu \mathrm{l}$ of PCR forward primer $(10 \mu \mathrm{M}), 0.4 \mu \mathrm{l}$ of PCR reverse primer $(10 \mu \mathrm{M}), 0.2 \mu \mathrm{l}$ of ROX Reference Dye (50X), $1 \mu \mathrm{l}$ of mina53 cDNA or c-myc cDNA and $3 \mu \mathrm{l}$ of $\mathrm{dH}_{2} \mathrm{O}$. All the reactions were performed in triplicate. The sequence of primer pairs were: sense, GGG ACA CAA CAT TGG GTA TCA TCA and antisense, AAC ATG GGC AAT TCA GGC AGA for mina53; sense, CCA CAG CAA ACC TCC TCA CAG and antisense, GCA GGA TAG TCC TTC CGA GTG for c-myc; and sense, GTG AAG GTC GGA GTC AAC G and antisense, TGA GGT CAA TGA AGG GGT C for GAPDH (reference gene). The reactions were carried out at $95^{\circ} \mathrm{C}$ for $30 \mathrm{sec}$ initially followed by 40 cycles of $95^{\circ} \mathrm{C}$ for $5 \mathrm{sec}, 60^{\circ} \mathrm{C}$ for $31 \mathrm{sec}$ and $72^{\circ} \mathrm{C}$ for $30 \mathrm{sec}$. Reaction products were identified by agarose gel electrophoresis and GoldView staining. The threshold cycle $(\mathrm{Ct})$ of every target gene for each sample was assessed using the $2^{-\Delta \Delta \mathrm{Ct}}$ method $[\Delta \Delta \mathrm{Ct}=$ (tumor gene $\mathrm{Ct}-\mathrm{GAPDH} \mathrm{Ct}$ ) - (normal epithelial gene $\mathrm{Ct}$ - GAPDH $\mathrm{Ct}$ )]. A fold-change $\geq 2$ was determined to be high expression.

Western blot analysis. Cells from 12 pairs of samples were lysed in a mixed buffer (9.5 mol/l urea, $65 \mathrm{mmol} / \mathrm{l}$ DTT, $4 \%$ CHAPS, $0.2 \%$ IPG buffer) for $1 \mathrm{~h}$ in an ice-bath and then centrifuged at $12,000 \mathrm{rpm}$ for $1 \mathrm{~h}$ at $4^{\circ} \mathrm{C}$. Sample proteins $(20 \mu \mathrm{g})$ were subjected to $8 \%$ sodium dodecylsulfate-polyacrylamide gel electrophoresis followed by electrotransfer onto a polyvinylidene difluoride microporous membrane (Millipore, Bedford, MA, USA) and then blocked with 5\% skim milk/0.01\% Tween for $2 \mathrm{~h}$ at room temperature. After treatment with rabbit anti-Mina53 polyclonal antibody at a dilution of 1:2,500 (Abcam Biotechnology), rabbit anti-c-Myc monoclonal antibody (Bioget Technology) at a dilution of 1:1,000 or HRP-conjugated rabbit anti-GAPDH monoclonal antibody (Shanghai Kangcheng Biotechnology Co., Ltd., Shanghai, China) at a dilution of 1:3,000 at $4^{\circ} \mathrm{C}$ overnight and incubated with HRP-conjugated secondary antibodies 
except for GAPDH at room temperature for $1 \mathrm{~h}$, blots were then detected with enhanced chemiluminescence for $1 \mathrm{~min}$ (Pierce Biotechnology).

Immunohistochemical staining for anti-Mina53. Routinely processed FFPE serial sections $(4 \mu \mathrm{m})$ were mounted on coated slides and deparaffinized in xylene and graded alcohol. After pretreatment with $3 \% \mathrm{H}_{2} \mathrm{O}_{2}$, deparaffinized $4-\mu \mathrm{m}$ tissue sections were autoclaved for Mina53. After treatment with $5 \%$ non-immune goat serum, the sections were incubated overnight at $4{ }^{\circ} \mathrm{C}$ with the anti-Mina53 polyclonal antibody at a dilution of 1:500 (Abcam Biotechnology), followed by peroxidase-labeled goat anti-mouse or goat anti-rabbit IgG Fab'. Color was developed with 3,3-diaminobenzidine before the light counterstaining with hematoxylin. The sections were then air-dried, coverslipped and observed with an Olympus BX51 microscope (Olympus Optical Co., Ltd., Tokyo, Japan).

Evaluation of immunostaining. The positive staining intensity of cells was scored as follows: 0 , no staining; 1 , shallow brown; 2 , brown; 3 , dark brown. The percentage of positive cells was divided into 4 levels: $0, \leq 10 \%$ positive cells; $1,11-50 \%$ positive cells; $2,51-75 \%$ positive cells; $3,>75 \%$ positive cells. The total score for the staining of samples was calculate by multiplication of the intensitiy and percentage scores: $0,(-) ; 1-2,(+) ; 3-4$, $(++)$; 5-9, (+++). Each score $\geq 3-4(++)$ was considered to be high expression.

Statistical analysis. The comparison of the mRNA and proteins between the malignant cells and the adjacent nonmalignant cells was tested using Wilcoxon signed rank test, and the relationship between the mRNA or protein of mina53 and c-Myc was checked by Pearson correlation analysis. The staining index ratio of Mina53 was compared between different tissues using ANOVA analysis of variance. The correlation between Mina53 expression and Lauren's type was examined using $\chi^{2}$ test, and the same method was carried out between Mina53 expression and the various clinicopathological factors in IGC and DGC, respectively. Crude survival curves were calculated using the Kaplan-Meier method. P-values $<0.05$ were assigned to indicate statistically significant results. All statistical analyses were carried out using SPSS 16.0 (SPSS, Inc., Chicago, IL, USA).

\section{Results}

Expression and correlation of mina 53 and $c-M y c R N A$. When compared with the adjacent normal epithelial tissues, mina53 and c-myc mRNA expression in the malignant tissue was highly increased $(\mathrm{P}<0.05$ and $\mathrm{P}<0.01)$ as determined using real-time quantitative PCR. Mina53 expression was higher (fold-change $\geq 2$ ) in 9 cases and $\mathrm{c}-M y c$ expression was higher (fold-change $\geq 2$ ) in 12 cases (Fig. 1). A significant positive correlation between mina53 mRNA and c-myc mRNA in the gastric carcinoma was noted $(\mathrm{r}=0.58, \mathrm{P}<0.05)$.

Expression of Mina53 and c-Myc protein. The intensity of the band for Mina53 in the malignant tissue was increased when comparing to that in the adjacent normal epithelial samples in
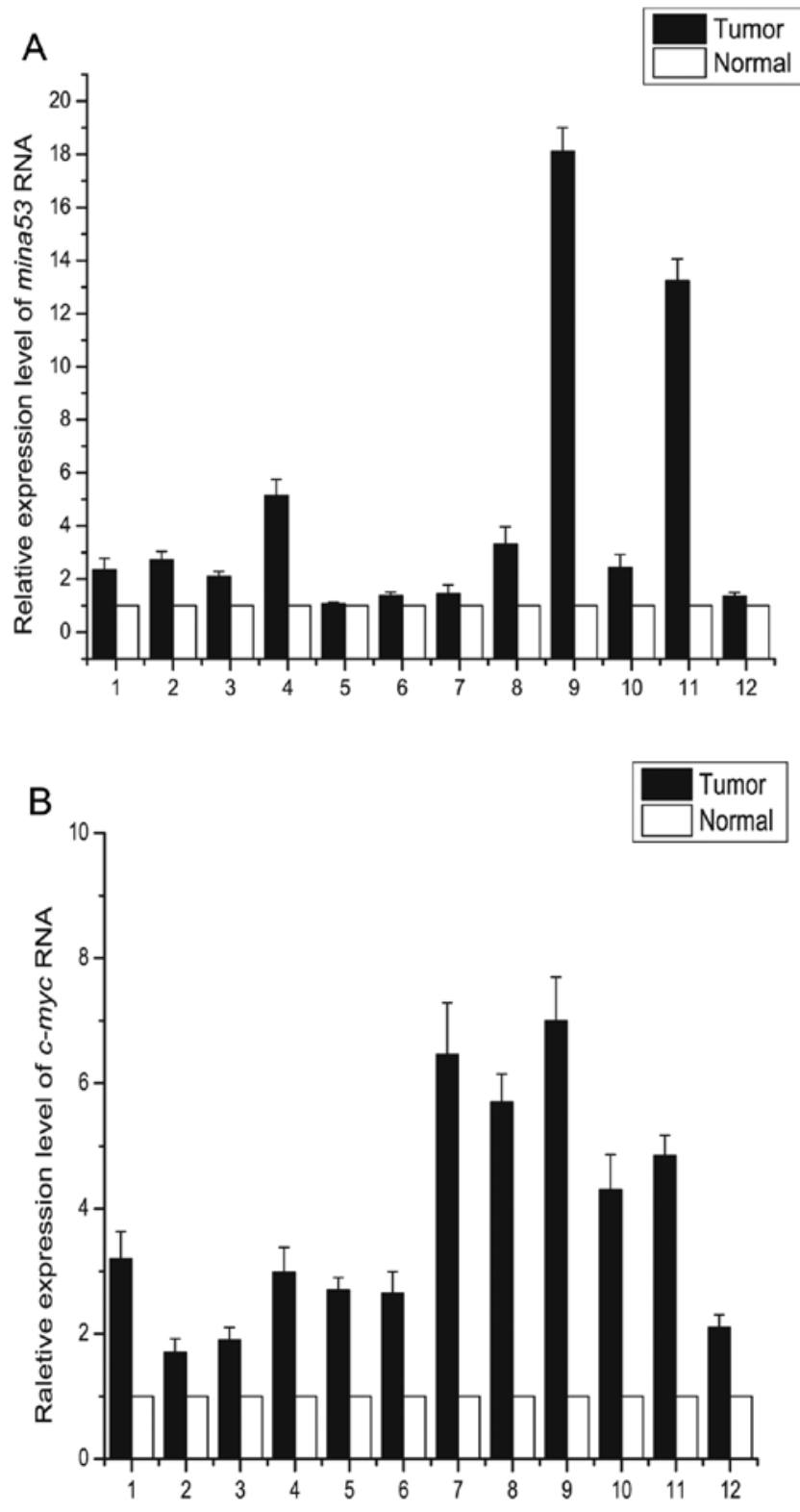

Figure 1. Overexpression of mina53 and c-myc mRNA in gastric cancer was validated in 12 pairs of gastric adenocarcinoma tissue samples by real-time quantitative PCR. Pooled RNAs extracted from each normal epithelial tissue were used as the calibrator $\left(2^{-\Delta \Delta \mathrm{Ct}}=1\right)$.

all 12 cases $(\mathrm{P}<0.01)$ (Fig. 2), and the expression level of c-Myc was found to be higher in malignant cells when compared to that in the adjacent normal epithelial tissues $(\mathrm{P}<0.05)$. Nevertheless, the c-Myc expression level was observed to be lower in the malignant than that in the matched non-malignant tissues in $3(25 \%)$ cases. The Mina53 expression was found to be significantly correlated with that of $\mathrm{c}-\mathrm{Myc}(\mathrm{r}=0.876$, $\mathrm{P}<0.01)$.

Immunohistochemistry of Mina53. The percentage of cases with overexpression of Mina53 was determined in normal gastric tissues $(0 \%)$, chronic atrophic gastritis without intestinal metaplasia (9.1\%), intestinal metaplasia (29.4\%), dysplasia (41.7\%) and IGC tissues (50\%). The frequency of the overexpression of Mina53 was progressively increased (Table I), with 


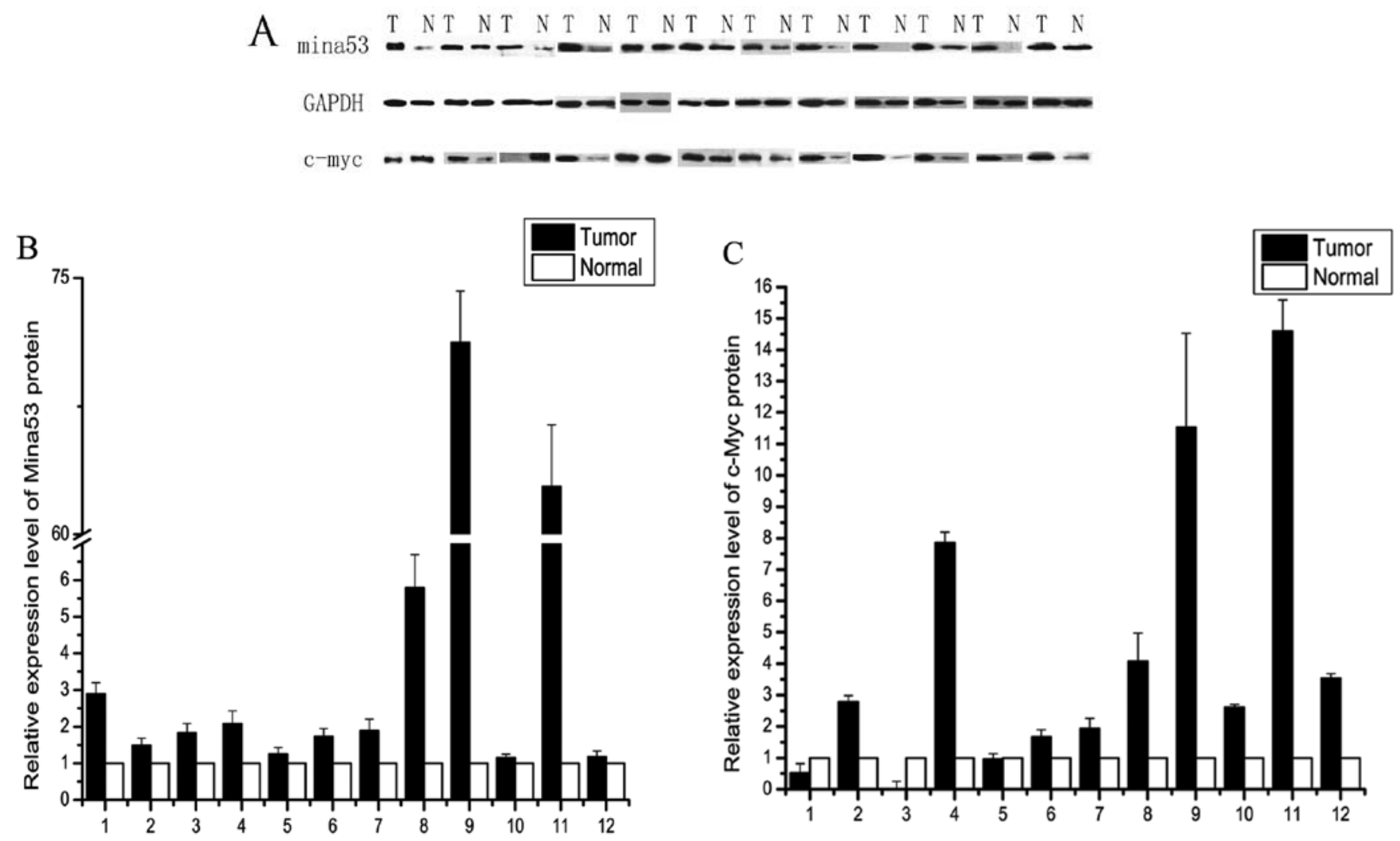

Figure 2. Western blot analysis of Mina53 and c-Myc in gastric tissues. (A) Total protein was extracted from paired tumor (T) and non-neoplastic (N) gastric tissues from 12 patients, electrophoresed, and immunoblotted with anti-Mina53 (top), anti-c-Myc (bottom) or anti-GAPDH (middle) antibodies. Overexpression of (B) Mina53 and (C) c-Myc protein in gastric cancer was validated in 12 pairs of gastric adenocarcinoma tissue samples by western blot analysis. Total proteins extracted from each normal epithelial tissue were used as a calibrator. The expression levels of Mina53 were higher in all tumor tissues than the levels in matched non-neoplastic tissues while the c-Myc expression level in cancer tissues was lower in 3 (25\%) cases (cases 1, 3 and 5).

Table I. Mina53 protein expression in the multistage tissues of gastric carcinogenesis.

\begin{tabular}{|c|c|c|c|c|c|c|c|}
\hline \multirow[b]{2}{*}{ Group } & \multirow[b]{2}{*}{ Total cases } & \multicolumn{4}{|c|}{ Mina53 protein expression } & \multirow[b]{2}{*}{ High expression (\%) } & \multirow[b]{2}{*}{ P-value } \\
\hline & & - & + & ++ & +++ & & \\
\hline Normal & 30 & 28 & 2 & 0 & 0 & 0 & \\
\hline NCAG & 44 & 23 & 17 & 4 & 0 & 9.1 & \\
\hline IM & 34 & 8 & 16 & 10 & 0 & 29.4 & 0 \\
\hline DYS & 36 & 4 & 17 & 10 & 5 & 41.7 & \\
\hline IGC & 30 & 3 & 12 & 9 & 6 & 50 & \\
\hline
\end{tabular}

NCAG, chronic non-atrophic gastritis; IM, intestinal metaplasia; DYS, dysplasia; IGC, intestinal gastric carcinoma.

a statistically significant difference $(\mathrm{P}<0.01)$. Mina53 expression was observed to be mainly localized in the nucleus and partly in the cytoplasm. Only a few cells in the neck of the glands eliminating mature foveola gastricae and proper gastric glands were detected to express Mina53 with low intensity in normal gastric tissues. The expression of Mina53 was increased in chronic atrophic gastritis without intestinal metaplasia which was still mainly located in the neck of the glands. In chronic atrophic gastritis with intestinal metaplasia, the expression of Mina53 was observed in intestinal metaplasia excluding proper gastric glands (Fig. 3).
Correlation between Mina53 overexpression and clinicopathological factors in intestinal-type gastric carcinoma (IGC) and diffuse-type gastric carcinoma $(D G C)$. No relationship was observed between the percentage of cases with Mina53 overexpression and patient gender and tumor site in both types of cancers. High expression of Mina53 was found to be correlated to age $(\mathrm{P}<0.05)$, tumor diameter $(\mathrm{P}<0.05)$, depth of invasion $(\mathrm{P}<0.01)$, lymph node metastasis $(\mathrm{P}<0.05)$, distant metastasis $(\mathrm{P}<0.05)$ and TNM staging $(\mathrm{P}<0.05)$ in IGC cases, while high expression of Mina53 was found to be correlated only with lymph node metastasis $(\mathrm{P}<0.01)$ in DGC cases. The Mina53 expression level was higher in the groups with age 


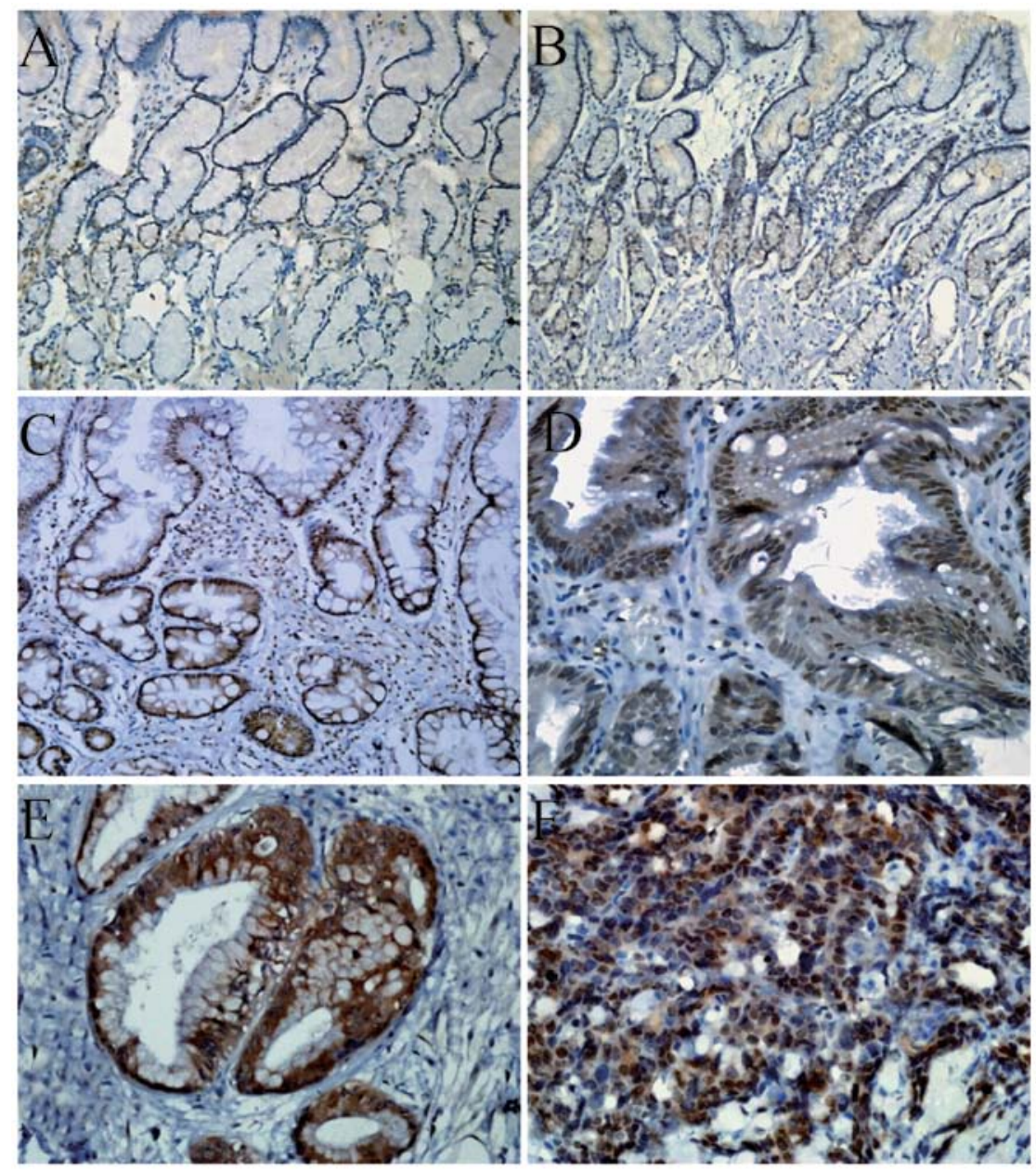

Figure 3. Immunoreactivity of Mina53 protein in the multistage tissues of intestinal-type gastric carcinogenesis. (A) Mina53 protein expression in normal gastric mucosa (x200). (B) Mina53 protein expression in CSG (x200). (C) Mina53 protein expression in IM (x200). (D) Mina53 protein expression in DYS (x400). (E) Mina53 protein expression in IGC (x400). (F) Mina53 protein expression in DGC (x400). CSG, chronic superficial gastritis; IM, intestinal metaplasia; DYS, dysplasia; IGC, intestinal gastric carcinoma; DGC, diffuse gastric carcinoma.

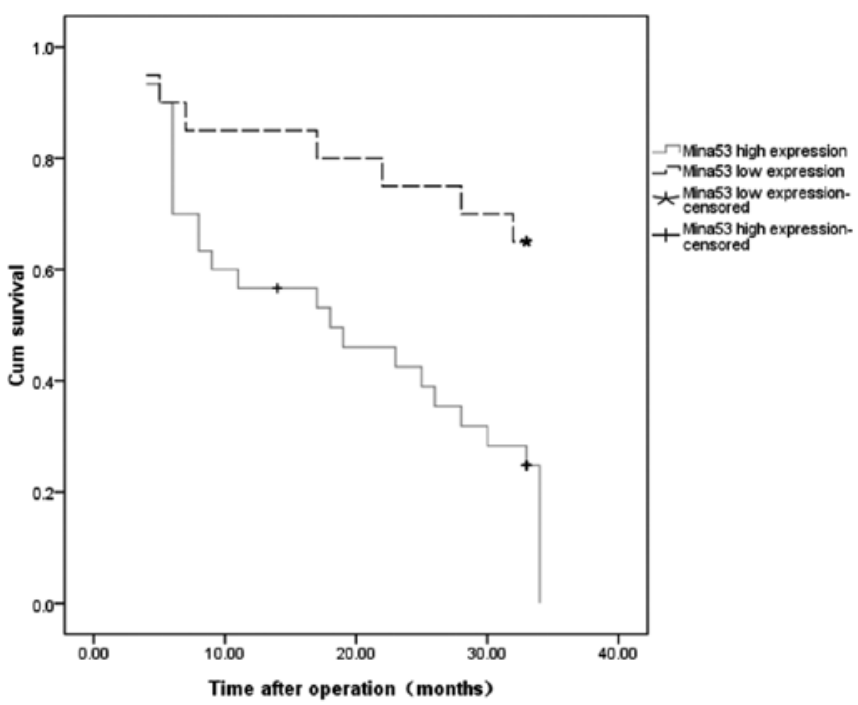

Figure 4. Correlation between Mina53 expression and patient survival rate. Fifty patients were divided into a low Mina53 expression group (group 1; $\mathrm{n}=8 ; 16.0 \%$ ) and a high Mina53 expression group (group 2; $\mathrm{n}=42 ; 82 \%$ ) and Kaplan-Meier curves for the two groups are shown. Patients with low Mina53 expression had markedly longer survival $(\mathrm{P}=0.007)$ than those with high Mina53 expression. The P-value was calculated using the $\log$ rank test. $\leq 63$ years, tumor diameter $>5 \mathrm{~cm}$, depth of invasion (T3+T4), lymph node metastasis, distant metastasis and TNM stage (II, III, IV) in the IGC cases (Table II).

Mina53 expression in relation to survival time. Fifty patients successfully followed up were divided into two groups according to low or high Mina53 expression. Crude survival curves were estimated for each group using the Kaplan-Meier method. The survival rate was lower in patients with tumors with high mina53 expression than in patients with tumors with low mina53 expression ( $\mathrm{P}=0.007$; Fig. 4).

\section{Discussion}

Mina53 has been identified as a novel myc-induced nuclear antigen. For quantitive analysis and to obtain 'pure' cells of interest, we firstly combined laser-capture microdissection with real-time quantitative PCR and western blot analysis to investigate the mina53 and c-myc expression in gastric carcinoma tissues and adjacent normal tissues without contamination.

A larger number of homogeneous cells were obtained using laser-capture microdissection for mRNA and protein analysis, 
Table II. Correlation between Mina53 expression and clinicopathological factors in IGC and DGC.

\begin{tabular}{|c|c|c|c|}
\hline & $\begin{array}{c}\text { Mina53 } \\
\text { expression } \\
\text { level }\end{array}$ & $\begin{array}{c}\text { Mina53 } \\
\text { over- }\end{array}$ & \\
\hline Features & $-/+\quad++/+++$ & $(\%)$ & P-value \\
\hline
\end{tabular}

Intestinal type

Gender

Male

$11 \quad 12$

Female

43

Age (years) ${ }^{\mathrm{a}}$

$\leq 63$

$>63$

$5 \quad 11$

Site

Antrum

Corpus ventriculi

Cardia

10

Tumor diameter $(\mathrm{cm})^{\mathrm{b}}$

$\leq 5$

$>5$

Depth of invasion

$\mathrm{T} 1+\mathrm{T} 2$

$\mathrm{T} 3+\mathrm{T} 4$

Lymph node metastasis

Negative

Positive

Distant metastasis

Negative

Positive

Tumor stage

I

II+III+IV

Diffuse type

Gender

Male

Female

Age (years) ${ }^{\mathrm{a}}$

$\leq 63$

$>63$

Site

Antrum

Corpus ventriculi

Cardia

Tumor diameter $(\mathrm{cm})^{\mathrm{b}}$

$\leq 5$

$>5$

Depth of invasion

$\mathrm{T} 1+\mathrm{T} 2$

$\mathrm{T} 3+\mathrm{T} 4$

Lymph node metastasis

Negative

Positive
4

52.2

42.9

0.03

68.8

28.6

0.617

57.1

36.4

60

0.025

35

80

0

23.1

70.1

0.001

15.4

76.5

0.021

40

100

0.025

20

65

$13 \quad 65$

0.565

75

80

0.565

75

80

0.764

68.8

84.6

80

0.352

69.2

81

60

0.334

79.3

40

91.7
Table II. Continued.

\begin{tabular}{|c|c|c|c|c|}
\hline \multirow[b]{2}{*}{ Features } & \multicolumn{2}{|c|}{$\begin{array}{c}\text { Mina53 } \\
\text { expression } \\
\text { level }\end{array}$} & \multirow{2}{*}{$\begin{array}{c}\text { Mina53 } \\
\text { over- } \\
\text { expression } \\
(\%)\end{array}$} & \multirow[b]{2}{*}{ P-value } \\
\hline & $-/+$ & $++/+++$ & & \\
\hline Distant metastasis & & & & 0.402 \\
\hline Negative & 6 & 16 & 72.7 & \\
\hline Positive & 2 & 10 & 83.3 & \\
\hline Tumor stage & & & & 0.126 \\
\hline I & 3 & 3 & 50 & \\
\hline II+III+IV & 5 & 23 & 82.1 & \\
\hline
\end{tabular}

IGC, intestinal-type gastric carcinoma; DGC, diffuse-type gastric car-

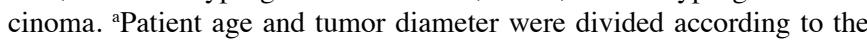
median value. -, negative; + , low-expression; $++/+++$, high-expression. $\mathrm{P}$-values $<0.05$ were considered to indicate statistically significant results.

and the levels of mina53 mRNA and protein expression were found to be highly elevated in tumor cells. The c-Myc expression was not always consistent with that of Mina53 by using western blot analysis (Fig. 2). A similar result was also reported in esophageal squamous cell carcinoma by Tsuneoka et al (9). In $3(25.0 \%)$ cases, the expression of c-Myc in tumor cells was lower than that in adjacent normal cells. Tsuneoka et al conjectured that proteins in the Myc/Mad/Max network or some other factor or factors which were able to control mina53 expression may be involved in this issue (9). Yet, the precise mechanisms remain unknown. This also demonstrated that it was a complicated mechanism for gene expression from mRNA to protein.

Immunohistochemical staining showed that the Mina53 expression level was increased stepwisely during the process of tumorigenesis in IGC. Teye et al (8) found that the expression level was increased in colon adenoma. These results suggest that the increase in Mina53 expression may be an early molecular event during gastric carcinogenesis. Thus, Mina53 may be a potential marker for the early diagnosis of gastric cancer.

Teye et al (8) also noted that the expression of Mina53 was increased in all pathological grades of colon cancer, particularly in strongly invasive and metastatic cases. In the present study, we observed that there was a higher percentage of cases with high Mina53 expression in DGC (76.5\%) when compared with this percentage in IGC $(50.0 \%)$. In addition, the correlation between Mina53 overexpression and clinicopathological features also differed in IGC and DGC. A high expression of Mina53 was associated with age, the diameter of the tumor, depth of invasion, lymph node metastasis, distant metastasis and TMN stage in IGC cases; however, high expression of Mina53 was correlated with only lymph node metastasis in DGC, exhibiting some differences from what was previously described. These results confirm that IGC and DGC have different histogenetic pathways (17) and suggest that mina53 may participate in lymph node metastasis in DGC. In the present study, we found that the staining index of Mina53 
was associated with the prognosis of patients with gastric carcinomas by a Kaplan-Meier plot, and the prognosis of patients with elevated expression of Mina53 was poor. A similar result was also found in esophageal squamous cell carcinomas (9) and advanced renal cell carcinomas (18). These findings suggest that Mina53 may serve as a potential marker for diagnosis and prognosis in a subset of gastric cancer patients, particularly DGC. However, in a study by Komiya et al (19), patients with high Mina53 expression were found to have a more favorable prognosis than those with low Mina53 expression. The exact mechanism is still needed to be investigated.

In conclusion, high expression of Mina53 was detected in gastric carcinoma and may be an early molecular events in tumorigenesis. It was found to be closely correlated with many dlinicopathological factors, and Mina53 may be a potential molecular marker for diagnosis, molecular classification and prognosis of gastric cancer. Elucidation of the mechanism of Mina53 in tumorigenesis and tumor progression may provide a novel therapeutic target for gastric adenocarcinoma.

\section{Acknowledgements}

We thank Mr. Yan-Shen Peng for preparing serial sections of the tissues. The authors are indebted to all patients who participated in the study as well as the surgeons who aided in the treatment of these patients. The present study was supported by grants from the National key Basic Research and Development Program (973) of China (no. 2010CB529304).

\section{References}

1. Huang CY, Chen YM, Zhao JJ, et al: Decreased expression of transcription elongation factor A-like 7 is associated with gastric adenocarcinoma prognosis. PLoS One 8: e54671, 2013.

2. Wang L, Huang X, Chen Y, Jin X, Li Q and Yi TN: Prognostic value of TP/PD-ECGF and thrombocytosis in gastric carcinoma Eur J Surg Oncol 38: 568-573, 2012.

3. Pourhoseingholi MA, Moghimi-Dehkordi B, Safaee A, Hajizadeh E, Solhpour A and Zali MR: Prognostic factors in gastric cancer using log-normal censored regression model. Indian J Med Res 129: 262-267, 2009.

4. Henning GT, Schild SE, Stafford SL, et al: Results of irradiation or chemo irradiation following resection of gastric adenocarcinoma. Int J Radiat Oncol Biol Phys 46: 589-598, 2000.
5. Gostissa M, Ranganath S, Bianco JM and Alt FW: Chromosomal location targets different MYC family gene members for oncogenic translocations. Proc Natl Acad Sci USA 106: 2265-2270, 2009.

6. Ruggero D: The role of Myc-induced protein synthesis in cancer. Cancer Res 69: 8839-8843, 2009.

7. Tsuneoka M, Koda Y, Soejima M, Teye K and Kimura H: A novel myc target gene, mina53, that is involved in cell proliferation. $\mathrm{J}$ Biol Chem 277: 35450-35459, 2002.

8. Teye K, Tsuneoka M, Arima N, et al: Increased expression of a Myc target gene Mina53 in human colon cancer. Am J Pathol 164: 205-216, 2004.

9. Tsuneoka M, Fujita $\mathrm{H}$, Arima $\mathrm{N}$, et al: Mina53 as a potential prognostic factor for esophageal squamous cell carcinoma. Clin Cancer Res 10: 7347-7356, 2004.

10. Ogasawara S, Komuta M, Nakashima O, Akiba J, Tsuneoka M and Yano H: Accelerated expression of a Myc target gene Mina53 in aggressive hepatocellular carcinoma. Hepatol Res 40: 330-336, 2010.

11. Tan XP, Zhang Q, Dong WG, Lei XW and Yang ZR: Upregulated expression of Mina53 in cholangiocarcinoma and its clinical significance. Oncol Lett 3: 1037-1041, 2012.

12. Wang Y, Antonopoulos DA, Zhu X, et al: Laser captured microdissection and metagenomic analysis of intact mucosaassociated microbial communities of human colon. Appl Microbiol Biotechnol 88: 1333-1342, 2010.

13. Wang L, Zheng L, Wang SY, Zhu TF and Zhu HG: Clonal analysis of gastric carcinoma and precancerous lesions and its relation to Ki-67 protein expression. Neoplasma 56: 48-55, 2009.

14. Lee HJ, Nam KT, Park HS, et al: Gene expression profiling of metaplastic lineages identifies $\mathrm{CDH} 17$ as a prognostic marker in early stage gastric cancer. Gastroenterology 139: 213-225, 2010.

15. Zhang Z, Li M, Zhang G, Fang P, Yao H, Xiao Z and Chen Z: Identification of human gastric carcinoma biomarkers by differential protein expression analysis using ${ }^{18} \mathrm{O}$ labeling and nanoLC-MS/MS coupled with laser capture microdissection. Med Oncol 27: 296-303, 2010.

16. Gutierrez-Gonzalez L, Graham TA, Rodriguez-Justo M, et al: The clonal origins of dysplasia from intestinal metaplasia in the human stomach. Gastroenterology 140: 1251-1260, 2011.

17. Gürbüz Y, Kahlke V and Klöppel G: How do gastric carcinoma classification systems relate to mucin expression patterns? An immunohistochemical analysis in a series of advanced gastric carcinomas. Virchows Arch 440: 505-511, 2002.

18. Ishizaki H, Yano H, Tsuneoka M, et al: Overexpression of the myc target gene Mina53 in advanced renal cell carcinoma. Pathol Int 57: 672-680, 2007.

19. Komiya K, Sueoka-Aragane N, Sato A, et al: Expression of Mina53, a novel c-Myc target gene, is a favorable prognostic marker in early stage lung cancer. Lung Cancer 69: 232-238, 2010 . 